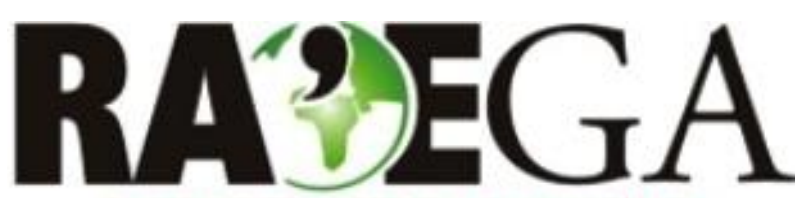

O ESPACYO GEOGRÁFICO EM ANÁLISE

\title{
LEVANTAMENTO COM VEÍCULO AÉREO NÃO TRIPULADO PARA GERAÇÃO DE MODELO DIGITAL DO TERRENO EM BACIA EXPERIMENTAL COM VEGETAÇÃO FLORESTAL ESPARSA
}

\section{UNMANNED AERIAL VEHICLE PHOTOGRAMMETRIC SURVEY FOR DIGITAL TERRAIN MODEL GENERATION OF A SPARSE FORESTED CATCHMENT}

\author{
Marcelo Ng Wei Ban Hung ${ }^{1 a}$, Tony Vinicius Moreira Sampaio ${ }^{1 b}$, Gilson Bauer Schultz ${ }^{1 c}$, Cesar Augusto \\ Crovador Siefert ${ }^{1 \mathrm{~d}}$, Daniel Ribeiro Lange ${ }^{1 \mathrm{e}}$, Fernando Helmuth Syring Marangon ${ }^{1 \mathrm{f}}$, Irani dos Santos ${ }^{1 \mathrm{~g}}$
}

\section{RESUMO}

A representação do relevo por meio dos modelos digitais do terreno (MDT) demanda do conhecimento das potencialidades e limitações das técnicas e instrumentos da aerofotogrametria. O levantamento com veículos aéreos não tripulados (VANT) e câmeras não métricas tem sido amplamente utilizado como método para obtenção de MDT devido a sua facilidade de operação e baixo custo. Entretanto, a geração do MDT a partir do modelo digital de superfície exige cuidados e pode adicionar erros ao modelo. Neste contexto, este artigo tem por objetivo avaliar a qualidade do MDT gerado por aplicação de procedimento semiautomático sem pontos de controle em campo, em área com presença de vegetação esparsa. $O$ modelo foi gerado com o VANT Phantom 3 Professional com altura média de voo de $60 \mathrm{~m}$ e sem a utilização de pontos de controle. Para a avaliação da acurácia e validação do MDT foram utilizados 354 pontos obtidos por técnicas de levantamento topográfico convencional. As diferenças altimétricas entre o MDT e o levantamento foram, em geral, inferiores a $0,5 \mathrm{~m}\left(R^{2}=0,99\right)$, sendo obtido um erro padrão de $0,29 \mathrm{~m}$ e um padrão de exatidão cartográfica de $0,49 \mathrm{~m}$, equivalente a um levantamento altimétrico classe A (1:5.000). Foi ainda elaborado um modelo digital da vegetação, sendo validado a partir de dados obtidos em campo para 54 árvores $\left(R^{2}=0,87\right.$ e erro padrão $\left.=0,54 \mathrm{~m}\right)$. Os resultados evidenciam a aplicabilidade da utilização de levantamento com VANT para obtenção de MDT em locais com vegetação florestal esparsa mediante a validação dos resultados com levantamento topográfico convencional.

Palavras-chave: modelagem digital do relevo, imagens de alta resolução, aerofotogrametria.

\section{ABSTRACT}

Terrain representation through digital terrain models (DTM) requires the knowledge of the potentialities and limitations of aerial photogrammetry techniques and devices. Unmanned aerial photogrammetric surveys using photos acquired by non-metric cameras has been widely used as a method to generate DTMs due to its usability and low cost. However, some wariness for DTM generation from the digital surface model (DSM) resulting from aerial photogrammetric surveys should be taken due the errors that could be added on this procedure. Here, the main objective was evaluate the DTM generated with a semi-automatic procedure without ground control points for a sparse forested area. The survey was carried out using an unmanned aerial vehicle (UAV) model Phantom 3 Professional with average flight height of $60 \mathrm{~m}$ and without ground control points. 354 elevation points acquired by a topographical survey were used for cartographic accuracy assessment and DTM validation (spatial resolution $=63$ $\mathrm{cm}$ ). The height differences between DTM and topographical survey elevation points were lower than $0,5 \mathrm{~m}$ with a standard error (SE) of $0,29 \mathrm{~m}$ and a standard cartographic accuracy of 0,49 m, corresponding to A class altimetric data survey (1:5.000). Digital forest canopy height model was derived from DTM and DSM and validated through field survey of 54 trees height $\left(R^{2}=0,87, S E=0,54 \mathrm{~m}\right)$. Results have showed the potential of unmanned aerial photogrammetric survey for DTM generation in sparse forested areas as a result of the DTM heights validated with elevation points from topographical surveys.

Key-words: digital terrain modeling, high resolution images, aerial photogrammetry.

Recebido em: 30/11/2017

Aceito em: 22/02/2018

\footnotetext{
${ }^{1}$ Universidade Federal do Paraná, Curitiba/PR.

amarcelo.hung1@gmail.com, btonysampaio@ufpr.br, cgilsonb.schultz@gmail.com, ${ }^{d}$ cesarsiefert@ufpr.br, eribeirolange@gmail.com,ffhsmarangon@gmail.com,girani69@gmail.com.
} 


\section{LEVANTAMENTO COM VEÍCULO AÉREO NÃO TRIPULADO PARA GERAÇÃO DE MODELO DIGITAL DO TERRENO EM BACIA EXPERIMENTAL COM VEGETAÇÃO FLORESTAL ESPARSA}

\section{INTRODUÇÃO}

As representações do relevo podem contribuir nos estudos das diferentes características e interações da paisagem, como a distribuição espacial da rede de drenagem, tipos de solo, vegetação e geologia (EVANS, 2012). Para isto, existem técnicas que representam a superfície terrestre a partir de pontos com coordenadas planialtimétricas.

Deste modo, os modelos digitais de representação do relevo que apresentam informações sobre a topografia, a vegetação e as construções, podem ser classificados como modelos digitais de superfície (MDS), uma vez que englobam as características do relevo e os objetos acima dele, sendo que o topo desses objetos é representado como a superfície do terreno (CRUZ et al., 2011). Por outro lado, quando o modelo representa somente as características do relevo sem considerar os objetos sob ele (vegetação e construções), pode ser classificado como modelo digital do terreno (MDT) (ARAKI, 2005).

Atualmente é possível obter essas informações sobre as características do relevo por meio de: interpolação de dados vetoriais obtidos via cartas topográficas ou aerolevantamento; plataformas orbitas equipados com sensores ópticos ou de radar; sensores Light Detection and Ranging (LIDAR); estação total; receptores de sinais Global Navigation Satellite System (GNSS); e Veículos Aéreos Não Tripulados (VANTs) (RODRIGUES, 2016).

Embora a Agencia Nacional de Aviação Civil - ANAC empregue o termo Aeronave Remotamente Pilotada (RPA), cuja a definição é aeronave não tripulada utilizada para fins não recreativos como uso comercial, corporativo ou experimental, o termo VANT é amplamente utilizado na literatura (HUGENHOLTZ et al., 2013; MANCINI et al., 2013; SILVA et al., 2015a; JÚNIOR et al., 2015; SILVA et al., 2016). Neste contexto, o levantamento com VANT constitui-se como um conjunto de operações com o objetivo principal de obter imagens aéreas de um determinado local, através de uma câmera acoplada, sendo necessário o registo e análise dos dados obtidos. Os VANTs podem ter suas trajetórias controlados pelo operador ou orientados por sistemas de navegação por satélite (GNSS) e podem capturar imagens sequenciais que são analisadas e processadas via software até a geração de produtos cartográficos como ortofotos, nuvens de pontos, modelos digitais de terreno e de superfície, os quais podem fornecer outros produtos como distâncias, alturas de objetos e volume.

Desta maneira, a partir dos VANTs é possível obter dados da superfície terrestre com grande nível de detalhe compatível com estudos em pequenas áreas como por exemplo, bacias experimentais. Além disso, o custo para aquisição e operação é relativamente baixo quando comparado com os demais sistemas convencionais (SILVA et al., 2014; SILVA et al., 2015a).

Diversos estudos analisaram a qualidade de MDSs e MDTs gerados por VANTs (HUGENHOLTZ et al., 2013; MANCINI et al., 2013; SILVA et al., 2015a; JÚNIOR et al., 2015; SILVA et al., 2016) utilizando voos automáticos com sobreposição longitudinal (>70\%) e lateral (>60\%) de imagens e avaliaram a acurácia do levantamento através do erro padrão (EP), que é calculado por meio dos resíduos das discrepâncias entre os dados medidos em campo com equipamentos de alta precisão como o GNSS e a estação total.

Segundo Ferreira (2014) e Silva et al., (2015a), para se obter um produto gerado através do VANT com precisão e confiabilidade, é necessário utilizar alvos pré-sinalizados em campo para orientar a similaridade entre as imagens sobrepostas durante a etapa de processamento. Porém, a utilização de alvos présinalizados requer custos adicionais significativos em relação ao planejamento, implantação e medição em campo (COSTA \& SILVA, 2012), podendo significar até $70 \%$ do tempo total de trabalho em um levantamento (FERREIRA, 2014). 


\section{LEVANTAMENTO COM VEÍCULO AÉREO NÃO TRIPULADO PARA GERAÇÃO DE MODELO DIGITAL DO TERRENO EM BACIA EXPERIMENTAL COM VEGETAÇÃO FLORESTAL ESPARSA}

Entretanto, dependendo da área a ser levantada, a identificação de alvos pré-sinalizados em campo como pontos de apoio pode ser uma tarefa difícil e inviável. Em casos de áreas florestais a vegetação dificulta e inviabiliza a visualização dos pontos de controle nas imagens levantadas.

Segundo Gaboardi \& Lübeck (2016), somente a banda $\mathrm{P} \quad(0,3$ a $1 \mathrm{GHz})$ da interferometria via Synthetic Aperture Radar
(SAR) consegue atravessar o dossel da vegetação e atingir o solo devido a capacidade de penetração de sua radiação eletromagnética, permitindo obter informações do relevo independente da cobertura vegetal (Figura 1). Deste modo, as câmeras acopladas aos VANTs conseguem identificar pontos do solo somente quando a vegetação ou edificações não bloqueiam sua visualização.
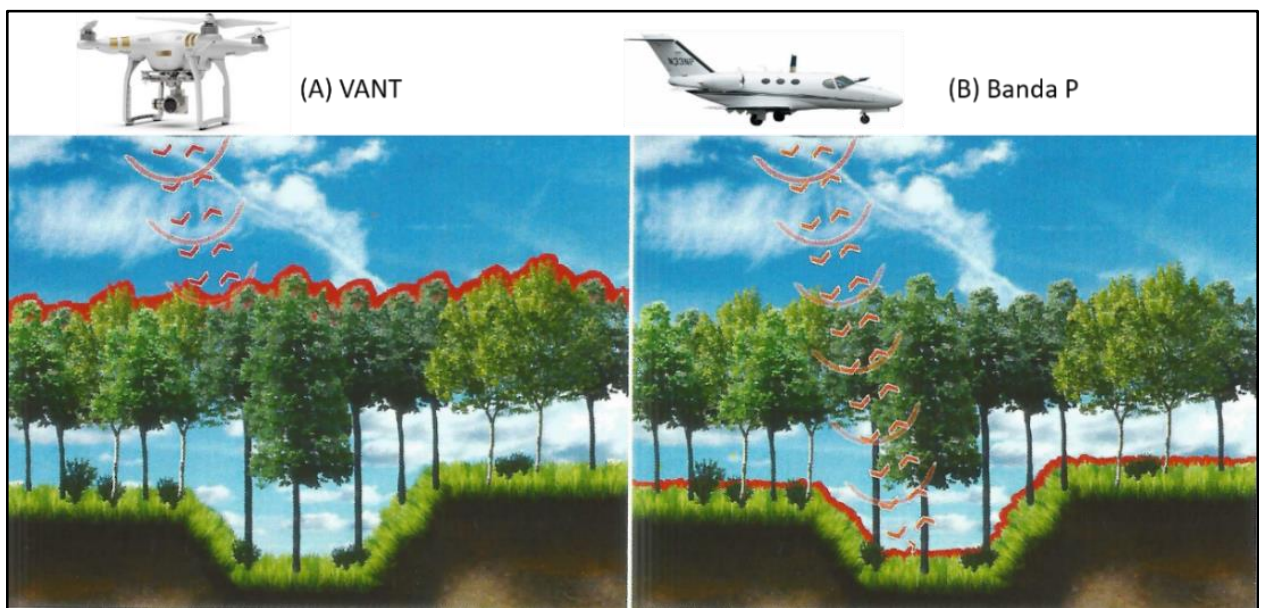

Figura 1 - Exemplo de penetração do sinal da câmera do VANT (A) e da banda P (B) em uma área de floresta densa. Fonte: adaptado de Gaboardi \& Lübeck (2016).

Outro fator que pode afetar a qualidade do levantamento é a presença de sombra nas feições das imagens levantadas, resultando em uma redução na identificação dos pontos de solo no processo de correlação entre as imagens e causando perdas de informação no modelo gerado (SILVA et al., 2015a). Desta maneira, os processos automáticos de classificação e filtragem da nuvem de pontos para a geração de MDS e MDT, podem enfrentar dificuldades ao processar imagens com presença de áreas sombreadas como em locais com presença de vegetação, declividades verticais e declividades com inclinação negativa, conforme demonstra a Figura 2.

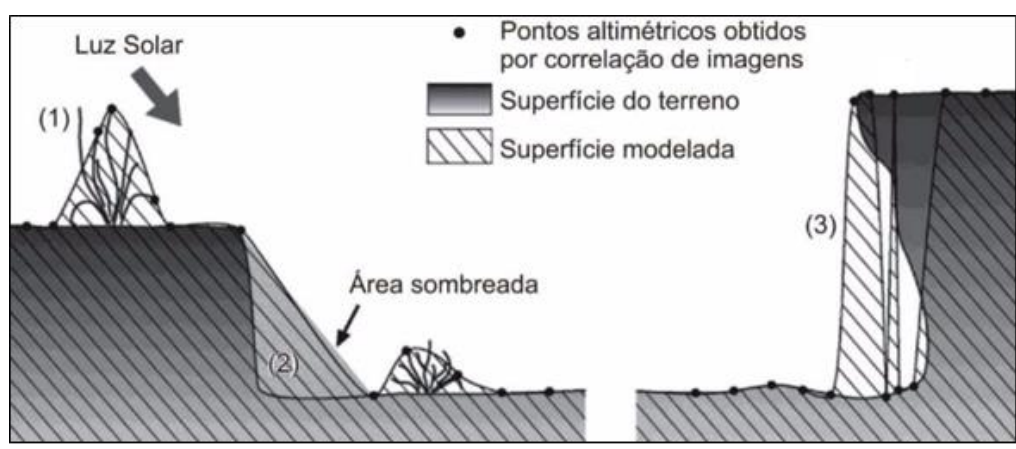

Figura 2 - Representação esquemática dos erros na criação automática de um MDS e MDT. (1) Vegetação; (2) declividade vertical e (3) declividade com inclinação negativa. Fonte: Adaptado de Marzolff \& Poesen (2009). 


\section{LEVANTAMENTO COM VEÍCULO AÉREO NÃO TRIPULADO PARA GERAÇÃO DE MODELO DIGITAL DO TERRENO EM BACIA EXPERIMENTAL COM VEGETAÇÃO FLORESTAL ESPARSA}

Neste contexto, o presente trabalho tem o objetivo de avaliar o MDT gerado de forma semiautomática com uso de VANT, sem pontos de controle em campo, em área com vegetação florestal esparsa. A avaliação da altimetria do MDT pós-processado foi realizada a partir de levantamento altimétrico realizado com estação total. Como produto secundário do processo obteve-se também a altura da vegetação de forma distribuída, denominado aqui de modelo digital da vegetação (MDV), o qual foi avaliado comparativamente com dados pontuais de altura da vegetação obtidos em campo.

\section{MATERIAIS E MÉTODOS}

O estudo foi realizado na bacia experimental do rio Saci $\left(0,18 \mathrm{~km}^{2}\right)$, operada pelo Laboratório de Hidrogeomorfologia (LHG - UFPR) e localizada no município de Rio Negrinho - SC (Figura 3). A cobertura do solo é predominantemente de vegetação florestal esparsa, com o uso da terra composto de reflorestamentos de Pinus taeda ssp (68,45\%) nas porções média e alta das vertentes, mata nativa secundária do tipo Floresta Ombrófila Mista (26,98\%) nas porções baixas das vertentes, e estradas não pavimentadas (4,57\%).

$O$ estudo foi realizado com o VANT Phantom 3 Professional com altura média de voo de $60 \mathrm{~m}$, sem utilização de pontos de controle. As orientações das coordenadas das imagens foram baseadas apenas nas coordenadas adquiridas pelo GNSS acoplado ao VANT que fornece informações sobre a posição do centro de cada imagem. Além disso, o levantamento foi realizado em um dia nublado para evitar que a sombra das feições afetasse a qualidade dos produtos gerados. A Tabela 1 apresenta o resumo das características do voo realizado.

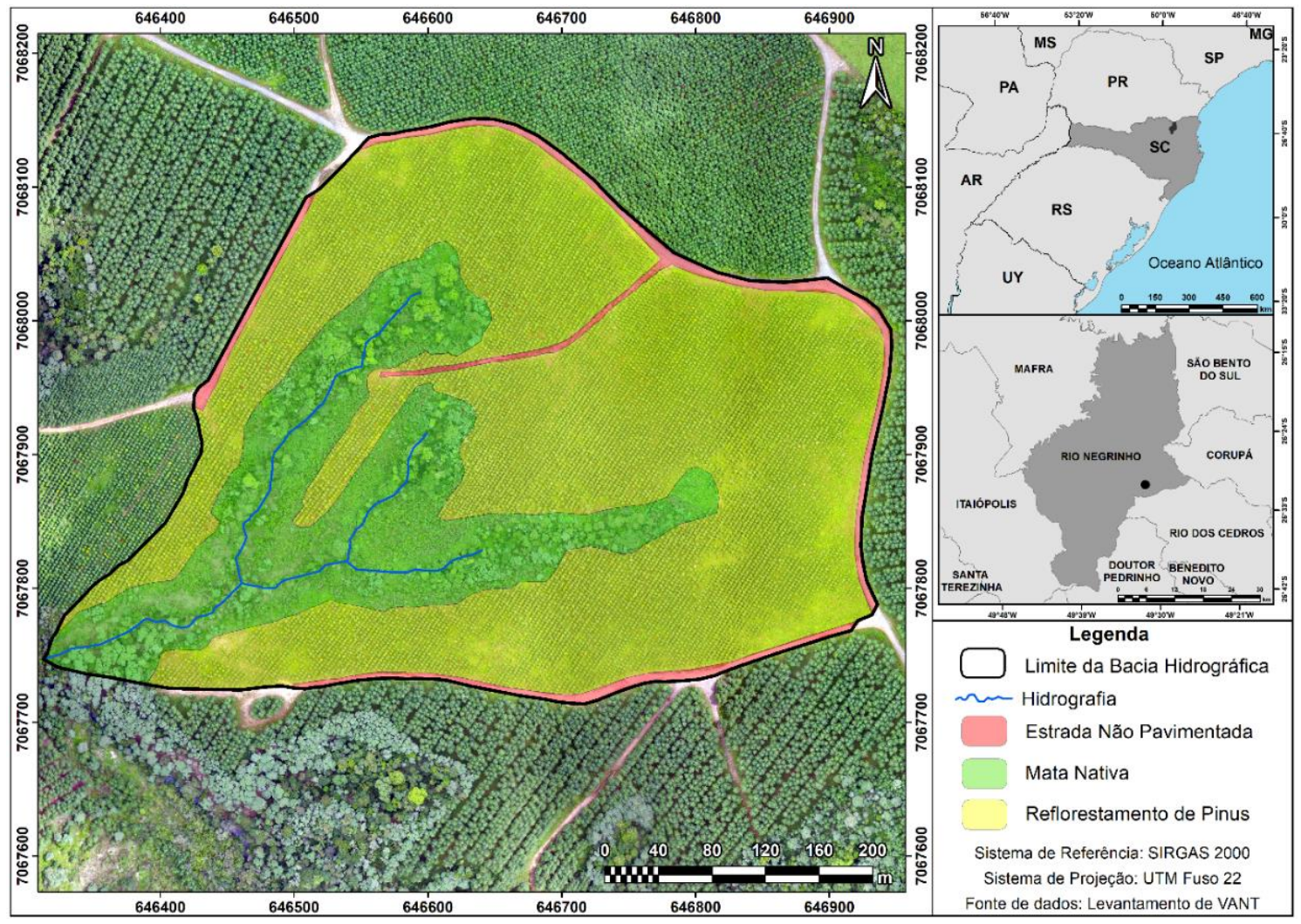

Figura 3 - Localização e uso da terra da bacia experimental do rio Saci. 


\section{LEVANTAMENTO COM VEÍCULO AÉREO NÃO TRIPULADO PARA GERAÇÃO DE MODELO DIGITAL DO TERRENO EM BACIA EXPERIMENTAL COM VEGETAÇÃO FLORESTAL ESPARSA}

\section{O VANT Phantom 3 Professional} necessita do controle e de um tablet ou celular (Figura 4). A câmera é fixada em uma plataforma de giro estabilizadora denominada gimball, que faz com que o movimento da câmera seja independente. Isso reduz o efeito da instabilidade da aeronave sobre a qualidade das imagens, o qual pode acarretar em problemas de escala e de geometria e, influenciar nos recobrimentos longitudinal e lateral (ALVES JR et al., 2014).

A Figura 5 representa o procedimento metodológico para aquisição, processamento e avaliação de dados obtidos pelo VANT com adaptações para as condições do presente trabalho. Na etapa do planejamento do voo foi definido a área de estudo e o plano de voo, que foi elaborado no software Pix4D Capture, instalado em um tablet com sistema operacional Android e conectado ao controle do VANT através do software Ctrl+DJI.

$\mathrm{Na}$ etapa de execução do voo, primeiramente foi verificado o funcionamento de todos os equipamentos (VANT, controle e tablet) e softwares. Após a verificação foi executado o plano de voo, sendo que este pode ser realizado de forma automática ou manual. Na etapa de pós voo foi realizado uma avaliação da qualidade dos dados obtidos, verificando se o trajeto do plano de voo foi executado sem interrupções e se durante o voo, o VANT não saiu da rota planejada (Figura 6). Estes problemas podem afetar o levantamento causando perda no recobrimento lateral das imagens (SILVA et al., 2015a).

Tabela 1 - Características do voo realizado.

\begin{tabular}{c|c}
\hline Características do Levantamento & Valores Observados \\
\hline Altura do voo em relação à base & $60 \mathrm{~m}$ \\
\hline Resolução espacial do MDS & $6,33 \mathrm{~cm}$ \\
\hline Resolução espacial do MDT & $63,3 \mathrm{~cm}$ \\
\hline Velocidade média de voo & $40 \mathrm{~km} / \mathrm{h}$ \\
\hline Número de imagens & 447 \\
\hline Recobrimento longitudinal & $70 \%$ \\
\hline Recobrimento lateral & $60 \%$ \\
\hline Modelo da câmera & DJI FC300X 3.6 RGB \\
\hline Resolução da câmera & $12 \mathrm{mp}$ \\
\hline Distância focal da câmera & $3,61 \mathrm{~mm}$ \\
\hline Área total levantada & $1,07 \mathrm{~km}{ }^{2}$ \\
\hline
\end{tabular}




\section{LEVANTAMENTO COM VEÍCULO AÉREO NÃO TRIPULADO PARA GERAÇÃO DE MODELO DIGITAL DO TERRENO EM BACIA EXPERIMENTAL COM VEGETAÇÃO FLORESTAL ESPARSA}

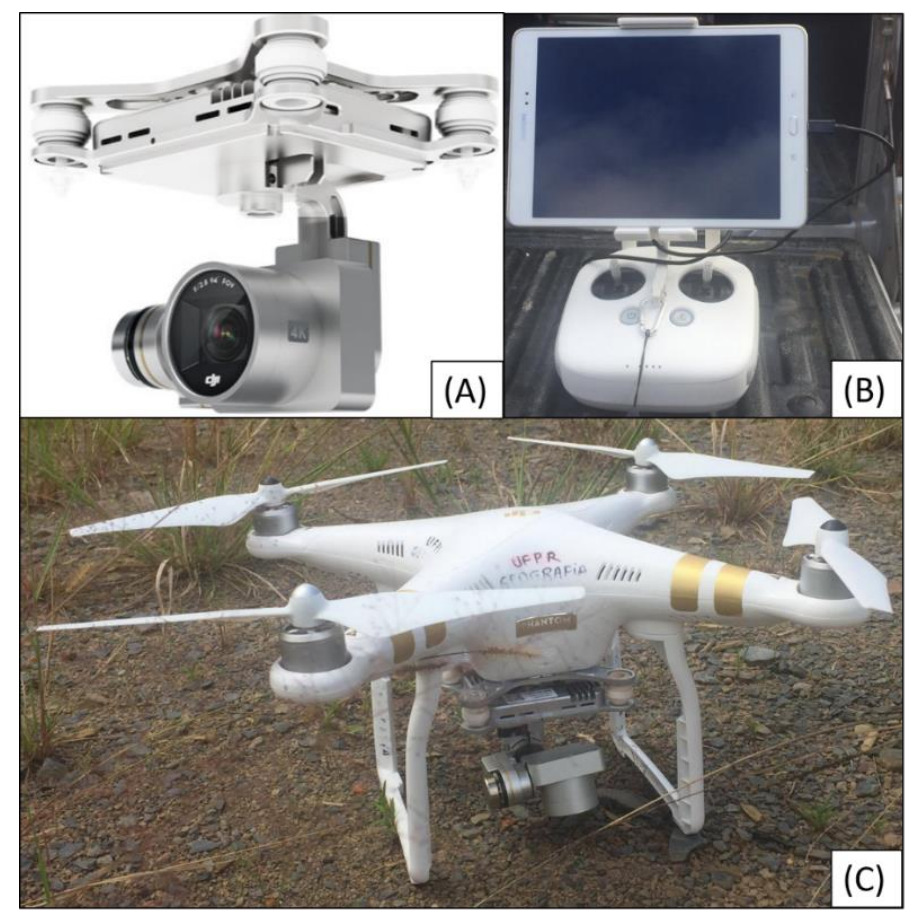

Figura 4 - Câmera (A), controle com tablet (B) e o VANT Phantom 3 Professional (C).

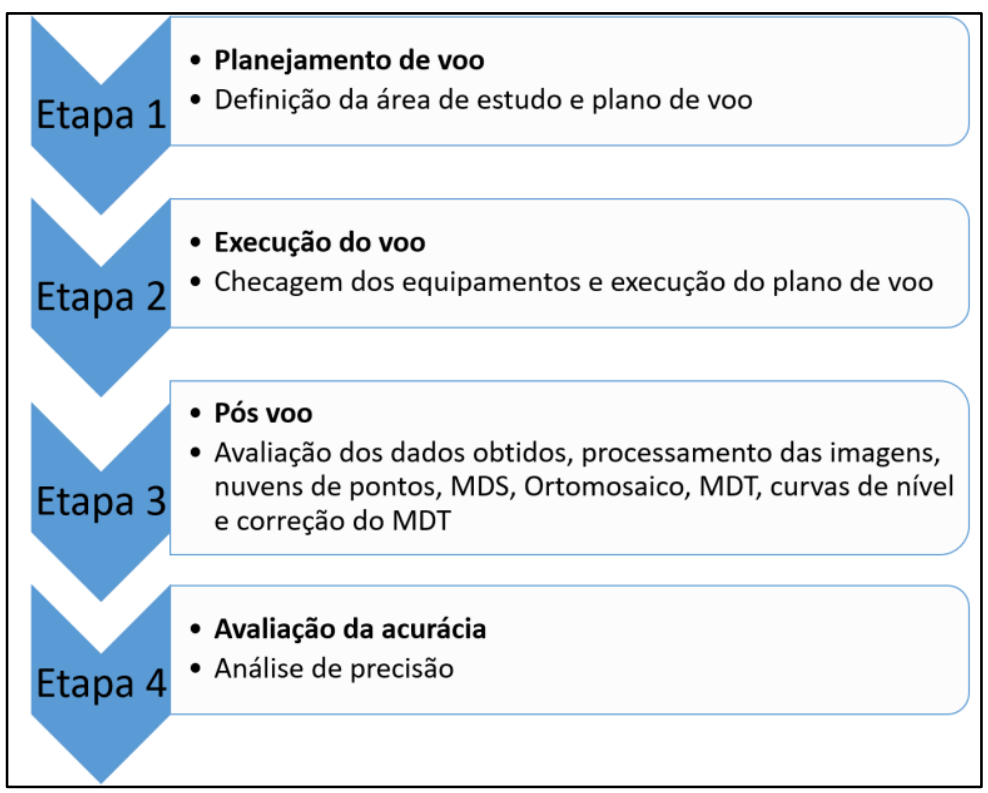

Figura 5 - Fluxograma dos procedimentos metodológicos para aquisição, processamento e avaliação dos dados obtidos pelo VANT. Fonte: adaptado de Silva et al., (2015b). 


\section{LEVANTAMENTO COM VEÍCULO AÉREO NÃO TRIPULADO PARA GERAÇÃO DE MODELO DIGITAL DO TERRENO EM BACIA EXPERIMENTAL COM VEGETAÇÃO FLORESTAL ESPARSA}

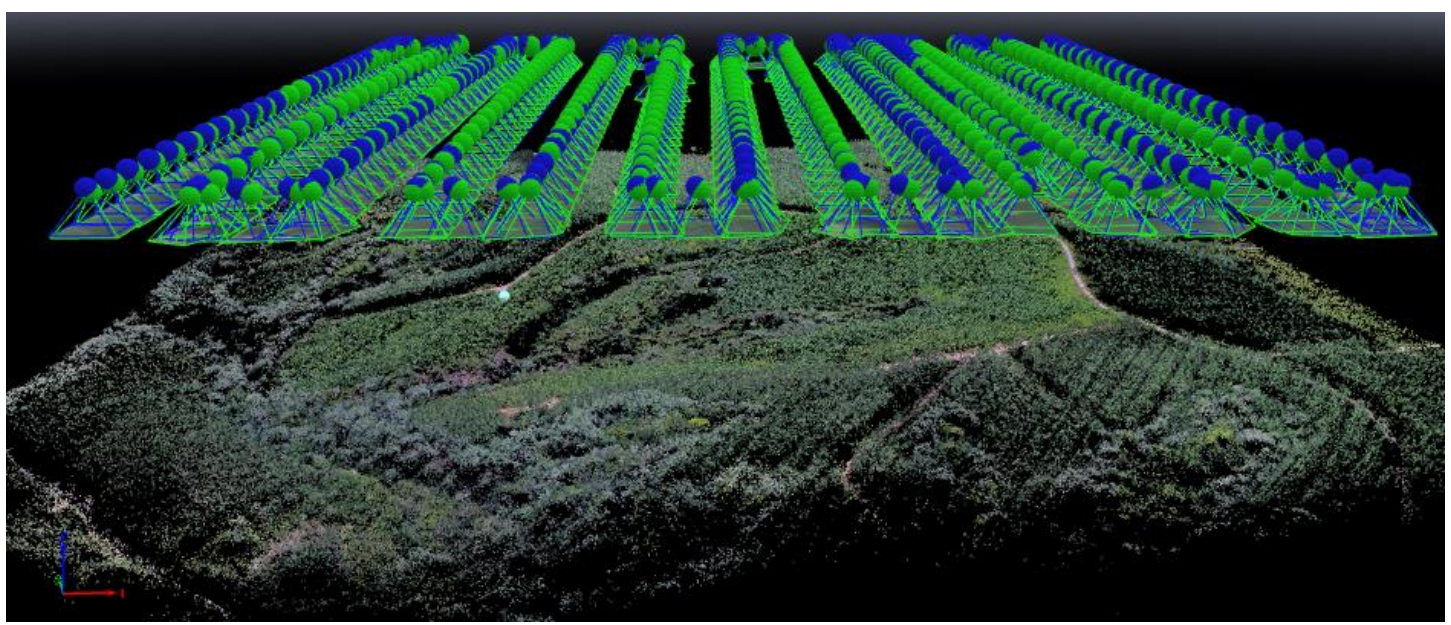

Figura 6 - Plano de voo, geração, classificação e filtragem da nuvem de pontos.

Posteriormente, as imagens foram processadas utilizando o software Pix4D Desktop versão trial (Figura 6) onde foi realizada a calibração automática da câmera, alinhamento das fotos, geração da nuvem de pontos, MDS, ortomosaico, classificação e filtragem automática da nuvem de pontos para gerar o MDT e curvas de nível, conforme descrito em PIX4D (2017). Cabe ressaltar que é necessário realizar um plano de voo com uma área maior do que a área de estudo, pois geralmente as bordas do mosaico final sofrem distorções devido à menor sobreposição de imagens. A Figura 7 demonstra o número de sobreposições de imagens para cada pixel, conforme o relatório do Pix4D Desktop.
A classificação e filtragem automática da nuvem de pontos baseiam-se no ângulo, altura e distância de cada ponto para diferenciar o relevo das demais feições (vegetação e construções) (UNGER et al., 2009; WESTOBY et al., 2012; TURNER et al., 2012; PIX4D, 2017) conforme a Figura 8. No primeiro passo é gerada a nuvem de pontos (Figura 8-A) que representa o relevo e as feições acima dele. No segundo passo (Figura 8B) é realizada a separação entre os pontos que pertencem somente ao relevo e as demais feições como a vegetação e construções. Por fim, no último passo (Figura 8-C) são selecionados apenas os pontos referentes ao relevo, que são interpolados visando a geração do MDT.

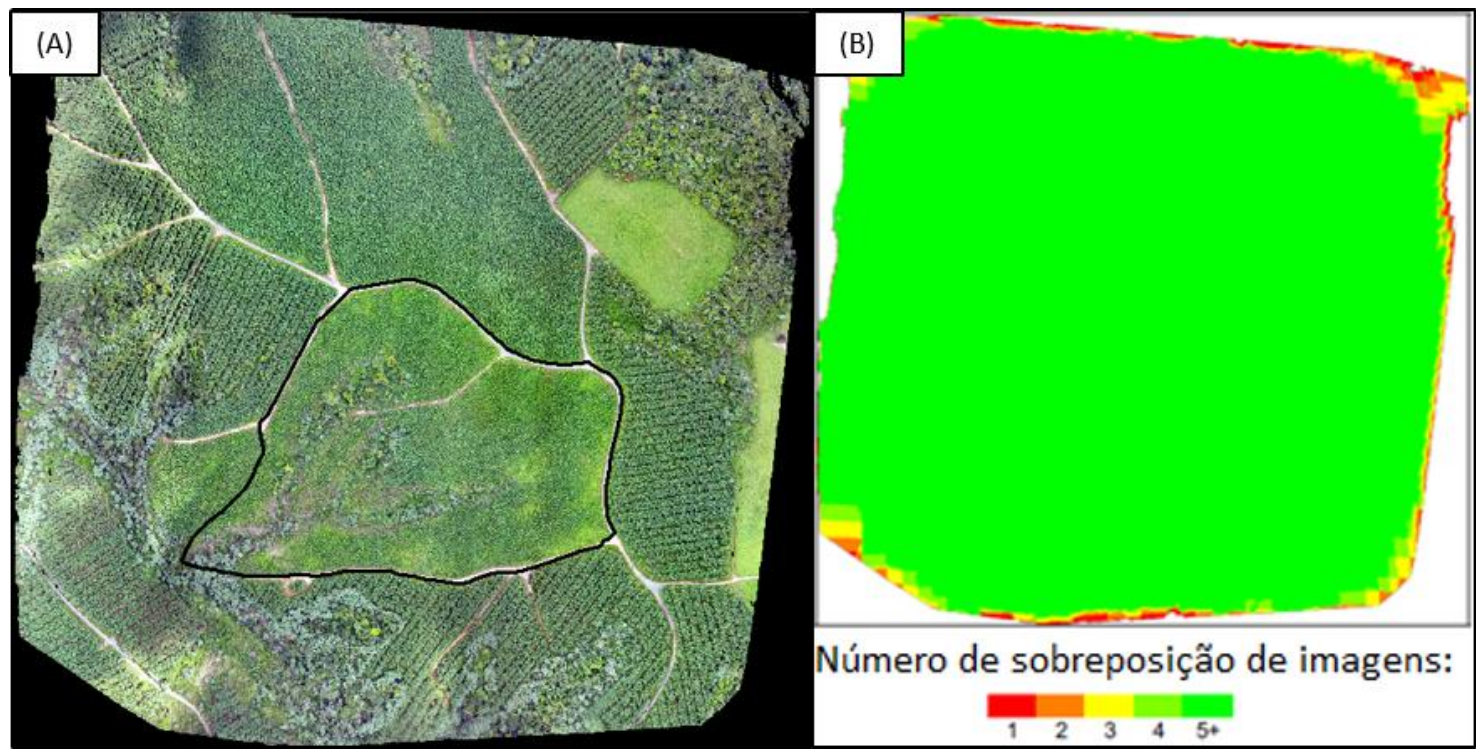

Figura 7 - Área total levantada (A) e número de sobreposição de imagens para cada pixel (B). 


\section{LEVANTAMENTO COM VEÍCULO AÉREO NÃO TRIPULADO PARA GERAÇÃO DE MODELO DIGITAL DO TERRENO EM BACIA EXPERIMENTAL COM VEGETAÇÃO FLORESTAL ESPARSA}

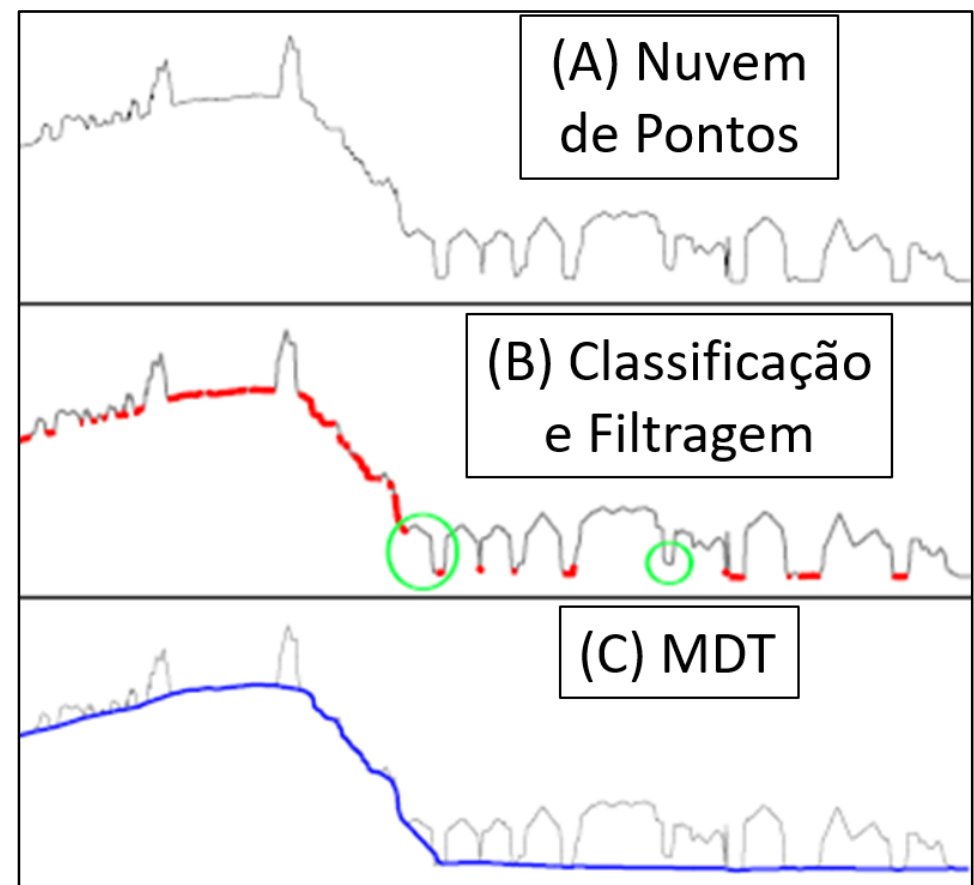

Figura 8 - Exemplo de geração do MDT através da classificação e filtragem automática. Fonte: Adaptado de Unger et al., (2009).

Entretanto, a classificação e filtragem automática pode gerar ruídos devido a densidade da vegetação presente na área de estudo, fazendo com que o Pix4D Desktop classifique em alguns casos, árvores de menor altura, como um ponto de solo em áreas de mata nativa e reflorestamento de pinus, onde a vegetação apresenta diferentes alturas e assim, enfatizando as dificuldades de gerar um MDT em áreas de floresta densa. Deste modo, foi necessário realizar a filtragem dos ruídos manualmente, a partir da exclusão de pontos que fugiram da tendência da superfície do relevo.

Por fim, na última etapa foi realizada a avaliação da acurácia do MDT final a partir da análise do erro padrão (EP) (Equação 1) conforme o Padrão de Exatidão Cartográfica dos Produtos Cartográficos Digitais (PEC-PCD) (Tabela 2), considerando as tolerâncias estabelecidas pela Diretoria de Serviços Geográficos do Exército Brasileiro na Norma da Especificação Técnica para Aquisição de Dados Geoespaciais Vetoriais de Defesa da Força Terrestre (ET-ADGV Defesa F Ter) (DSG, 2016), que estabelece critérios para que um dado espacial digital seja aceito como produto de referência do Sistema Cartográfico
Nacional (SCN) e para a Infraestrutura Nacional de Dados Espaciais (INDE).

Para a avaliação da acurácia foram utilizados 354 pontos obtidos via estação total modelo Leica FlexLine TSO2 com precisão de 1,5 $\mathrm{mm}$. As cotas levantadas em campo foram ajustadas para as cotas altimétricas a partir da amarração em uma RN implantada na área de estudo. Os valores de altimetria levantados através da estação total foram comparados com os valores de altimetria do MDT final e a partir disso, foi calculado o EP.

$\mathrm{EP}=\sqrt{\frac{\Sigma(z i-z t)^{2}}{n}}$

Onde $z i$ é a altitude do MDT $(\mathrm{m}), z t$ é a altitude do ponto de controle $(\mathrm{m})$ e $n$ é o número total de pontos de controle.

Conforme a DSG (2016), para que um produto digital possa ser aceito como produto de referência do SCN e para a INDE, 90\% dos erros dos pontos coletados no produto cartográfico $(1,6449 \times \mathrm{EP})$, quando comparados com os pontos de validação em campo utilizando equipamentos e métodos de alta precisão (qualidade três vezes superior à do produto analisado), devem apresentar os valores iguais ou 


\section{LEVANTAMENTO COM VEÍCULO AÉREO NÃO TRIPULADO PARA GERAÇÃO DE MODELO DIGITAL DO TERRENO EM BACIA EXPERIMENTAL COM VEGETAÇÃO FLORESTAL ESPARSA}

inferiores aos previstos no PEC-PCD, devendo ainda apresentar os valores de EP também iguais ou inferiores aos previstos na Tabela 2.

Como na geração dos modelos o software utiliza os dados dos metadados das imagens (coordenadas do sistema GNSS, altura do voo e dados do sistema inercial), podem ocorrer o surgimento de diferenças entre as cotas fornecidas pelo modelo de superfície e, as cotas cartográficas da área levantada (ou gap altimétrico). Neste caso, considerando que não houve utilização de pontos de controle em campo para geração do MDT, o modelo como um todo necessitou ser "rebaixado" 24,72 m por operação de álgebra de mapas para a cota de um ponto com referência altimétrica conhecida. Os 354 pontos da topografia foram utilizados exclusivamente para análise da qualidade altimétrica interna do modelo.

Tabela 2 - Padrão de Exatidão Cartográfica Altimétrica dos Pontos Cotados e do MDT, MDE e MDS para a produção de Produtos Cartográficos Digitais. Fonte: DSG (2016).

\begin{tabular}{c|c|c|c|c|c|c|c|c}
\hline \multirow{2}{*}{ PEC - PCD } & \multicolumn{2}{|c|}{$1: 1.000$} & \multicolumn{2}{c|}{$1: 2.000$} & \multicolumn{2}{c}{$1: 5.000$} & \multicolumn{2}{c}{$1: 10.000$} \\
& \multicolumn{2}{|c|}{$($ Eqd = 1 m) } & \multicolumn{2}{c|}{ (Eqd = 1 m) } & \multicolumn{2}{c}{ (Eqd = 2 m) } & \multicolumn{2}{c}{ (Eqd = 5 m) } \\
\cline { 2 - 9 } & PEC (m) & EP (m) & PEC (m) & EP (m) & PEC (m) & EP (m) & PEC (m) & EP (m) \\
\hline A & 0,27 & 0,17 & 0,27 & 0,17 & 0,54 & 0,34 & 1,35 & 0,84 \\
\hline B & 0,5 & 0,33 & 0,5 & 0,33 & 1 & 0,66 & 2,5 & 1,67 \\
\hline C & 0,6 & 0,4 & 0,6 & 0,4 & 1,2 & 0,8 & 3 & 2 \\
\hline D & 0,75 & 0,5 & 0,75 & 0,5 & 1,5 & 1 & 3,75 & 2,5 \\
\hline
\end{tabular}

Após a validação do MDT, a estimativa da altura da vegetação foi realizada subtraindo o MDT do MDS e gerado o modelo digital da vegetação (MDV), considerando que a área de estudo se constitui como uma bacia hidrográfica florestada e, portanto, não apresenta nenhuma outra feição acima da superfície do terreno além da vegetação. Para a validação do MDV foram levantadas as alturas individuais de 54 árvores medidas em campo utilizando uma haste telescópica graduada.

\section{RESULTADOS E DISCUSSÃO}

\subsection{MDS E MDT}

Depois do processamento das imagens obtidas pelo VANT, foi gerado o MDS com pixel de $6,33 \mathrm{~cm}$ e após a classificação, filtragem e correção dos ruídos, foi gerado o MDT com pixel de $63,3 \mathrm{~cm}$. Essa diferença no tamanho do pixel se dá por causa da filtragem e retirada dos pontos que pertenciam apenas ao MDS, ou seja, as feições acima da superfície do terreno (vegetação). Deste modo, os vazios deixados por essa filtragem, foram interpolados novamente para gerar o MDT. O MDS variou de $914 \mathrm{~m}$ até $986 \mathrm{~m}$ de altitude, enquanto que o MDT variou de 914 até $978 \mathrm{~m}$ de altura (Figura 9).

A Figura 9 apresenta ainda 6 pontos que exemplificam o uso da terra da bacia do rio Saci. A fotografia 1 representa áreas com as vegetações mais baixas da área de estudo. As fotografias 2 e 3 retratam o reflorestamento de Pinus taeda spp que atinge até $8 \mathrm{~m}$ de altura. A fotografia 4 demonstra a mata nativa que alcança até $22 \mathrm{~m}$ de altura. Já as fotografias 5 e 6 representam, além do reflorestamento de pinus, uma estrada não pavimentada que se constitui como um dos divisores da bacia hidrográfica. 


\section{LEVANTAMENTO COM VEÍCULO AÉREO NÃO TRIPULADO PARA GERAÇÃO DE MODELO DIGITAL DO TERRENO EM BACIA EXPERIMENTAL COM VEGETAÇÃO FLORESTAL ESPARSA}

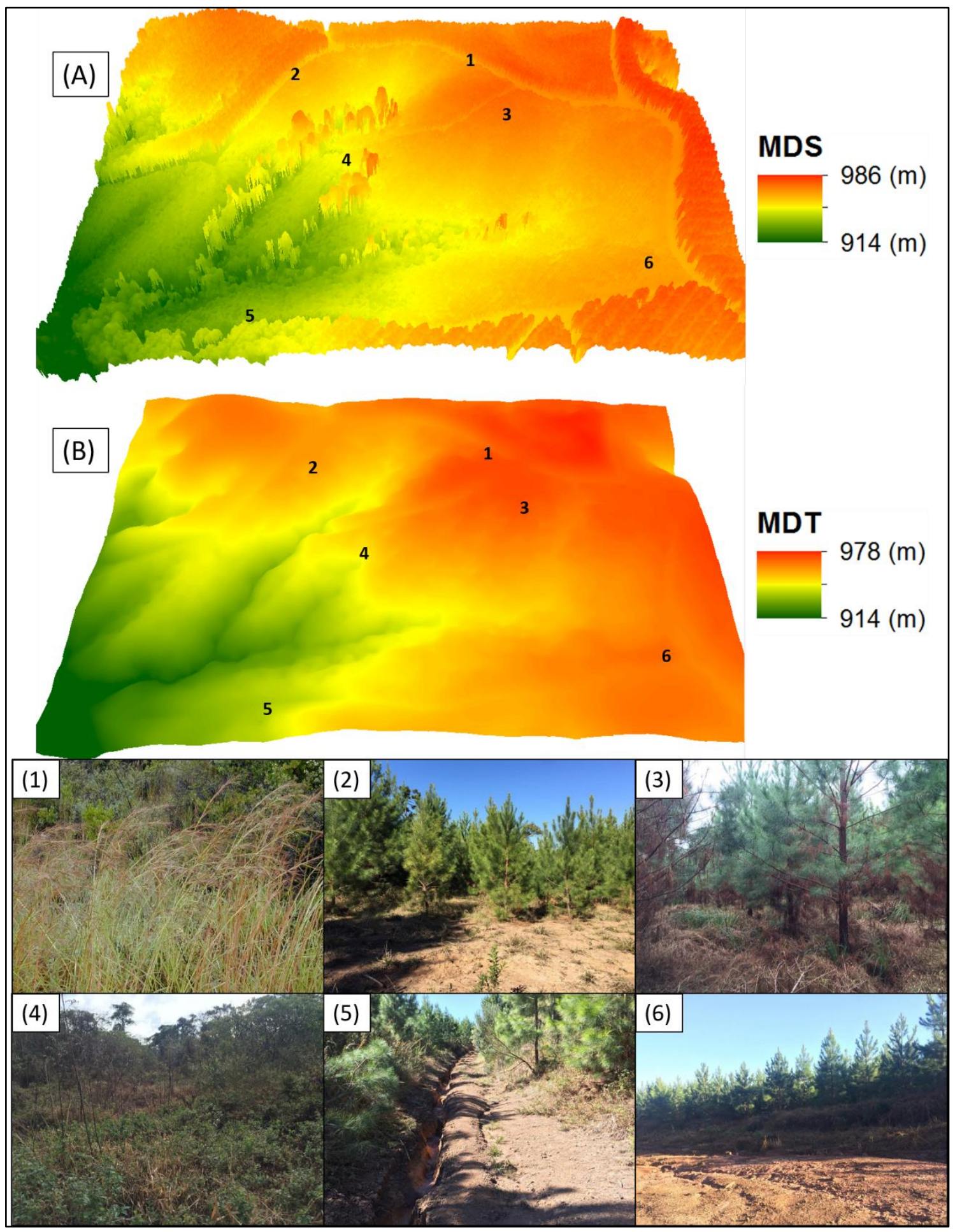

Figura 9 - MDS (A) e MDT (B) da bacia experimental do rio Saci.

\subsection{AVALIAÇÃO DA ACURÁCIA DO MDT}

A avaliação da acurácia do MDT foi realizada através da comparação com 354 pontos distribuídos pelas encostas e zona ripária obtidos por levantamento topográfico, onde cada ponto foi comparado com o valor do pixel do MDT (Figura 10). A diferença altimétrica máxima foi de 0,53 m e a mínima foi inferior a 0,01 m. A Figura 


\section{LEVANTAMENTO COM VEÍCULO AÉREO NÃO TRIPULADO PARA GERAÇÃO DE MODELO DIGITAL DO TERRENO EM BACIA EXPERIMENTAL COM VEGETAÇÃO FLORESTAL ESPARSA}

11 demonstra o comparativo entre a altimetria do MDT e os pontos do levantamento topográfico em relação à linha de tendência. De maneira geral, nota-se uma boa aderência do MDT aos dados de campo $\left(R^{2}=0,99\right)$.

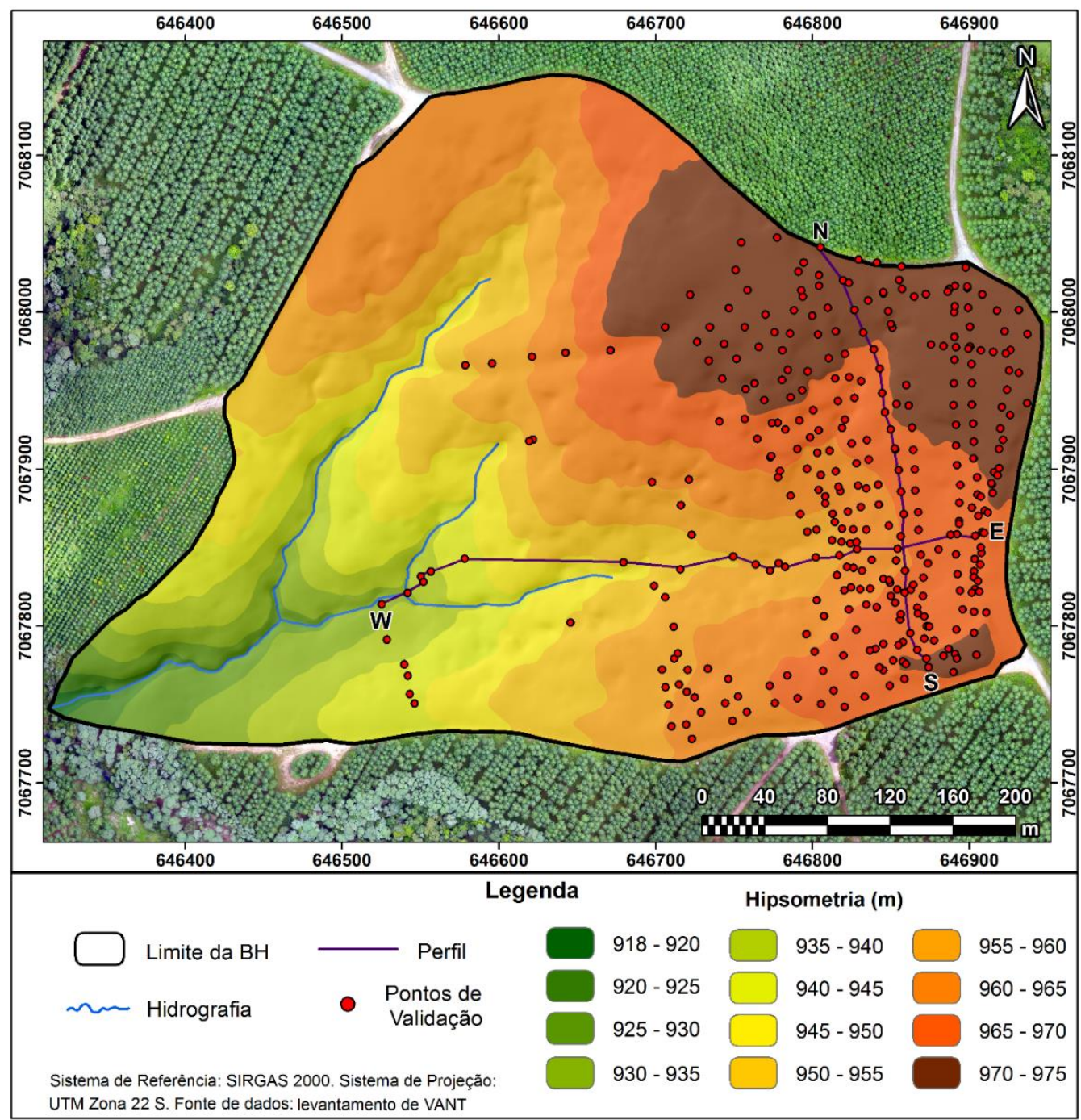

Figura 10 - Hipsometria da bacia experimental do rio Saci e pontos de validação.

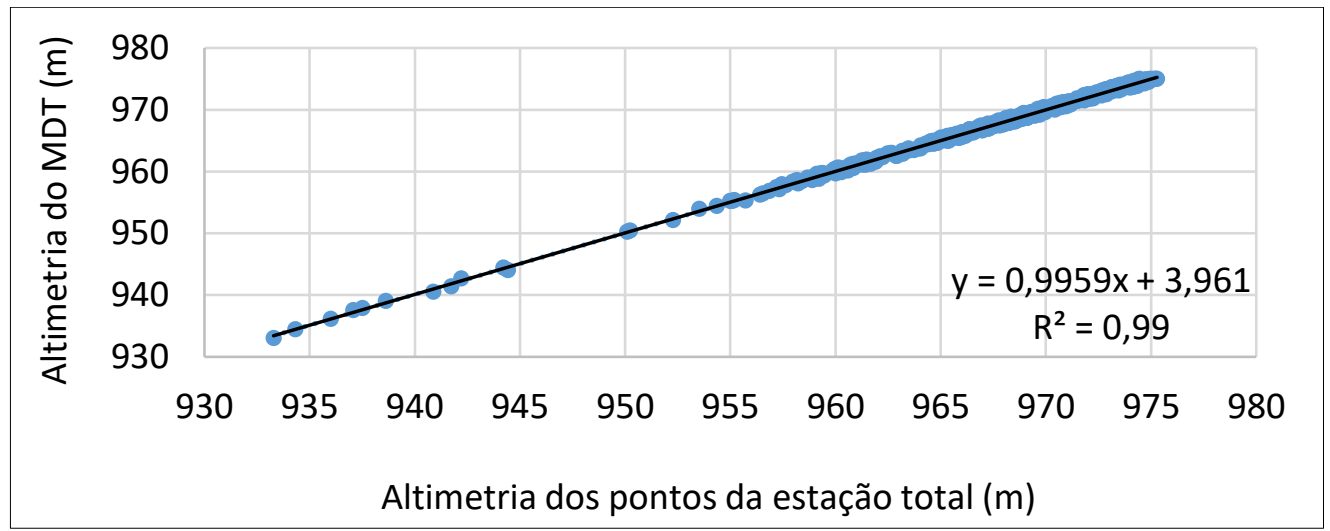

Figura 11 - Altimetria do MDT e altimetria dos pontos de validação em relação à linha de tendência. 


\section{LEVANTAMENTO COM VEÍCULO AÉREO NÃO TRIPULADO PARA GERAÇÃO DE MODELO DIGITAL DO TERRENO EM BACIA EXPERIMENTAL COM VEGETAÇÃO FLORESTAL ESPARSA}

A Figura 10 apresenta dois perfis (E-W e $\mathrm{N}-\mathrm{S}$ ) que exemplificam as discrepâncias entre os valores altimétricos do MDT e os pontos do levantamento topográfico, sendo que cada perfil possui 22 pontos de comparação e são apresentados na Figura 12. As maiores diferenças foram de $0,48 \mathrm{~m}$ e $0,47 \mathrm{~m}$ para os perfis $\mathrm{E}-\mathrm{W}$ e $\mathrm{N}$ $\mathrm{S}$, respectivamente. Por outro lado, a menor diferença foi inferior a $0,01 \mathrm{~m}$ para o perfil E-W e de $0,04 \mathrm{~m}$ para o $\mathrm{N}$-S. A Figura 12 representa essas discrepâncias em um gráfico comparativo, demonstrando que o MDT gerado a partir do VANT apresenta as características do relevo muito próximas dos valores medidos em campo.

Através do cálculo das discrepâncias para todos os 354 pontos de validação, foi calculado o EP conforme a Equação 1. Deste modo, o EP de 0,29 $\mathrm{m}$ e o valor do PEC de 0,49 $\mathrm{m}$. Analisando a Tabela 2, observa-se que os valores do EP e do PEC para a classe A são compatíveis com a escala 1:5.000.

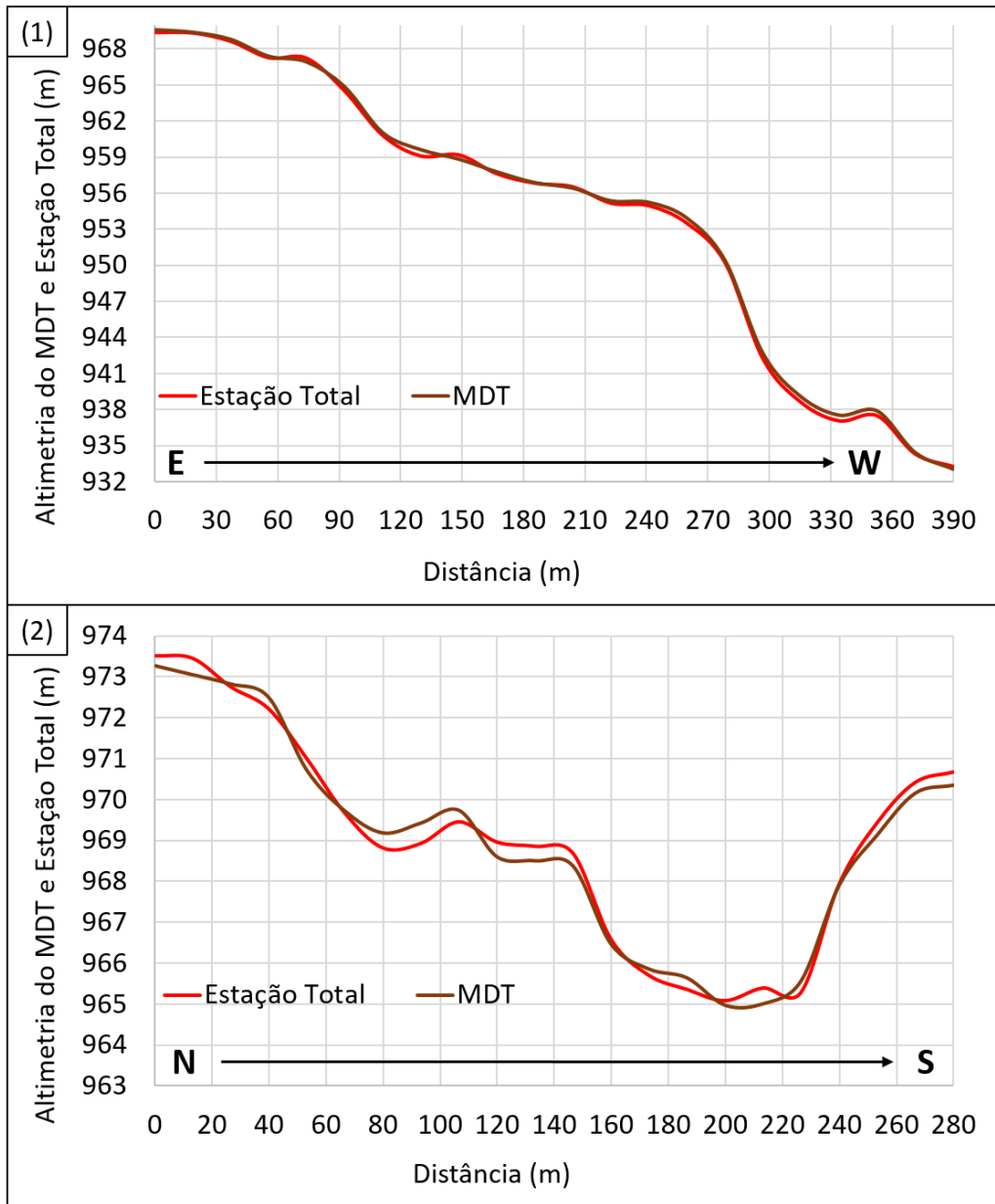

Figura 12 - Altimetria do MDT e altimetria dos pontos de validação para o perfil E-W (1) e perfil N-S (2).

Este valor ganha maior ênfase por se tratar de uma área com cobertura florestal. Como a vegetação é esparsa, parte dos pontos gerados correspondem a vegetação e parte ao solo, necessitando de filtragem para separação dos mesmos. Este procedimento será ainda mais difícil e complexo, quanto mais densa for a cobertura vegetal, podendo chegar ao ponto de não se obter pontos de altimetria correspondentes ao solo. Assim como evidenciado em Ponzoni et al., (2015) e Hung et al., (2017), à medida em que se aumenta a densidade da cobertura vegetal (aumento do índice de área foliar), a radiação eletromagnética na região do visível das câmeras e sensores tende 


\section{LEVANTAMENTO COM VEÍCULO AÉREO NÃO TRIPULADO PARA GERAÇÃO DE MODELO DIGITAL DO TERRENO EM BACIA EXPERIMENTAL COM VEGETAÇÃO FLORESTAL ESPARSA}

a perder informações do solo com o aumento das camadas de folhas da vegetação.

Gaboardi \& Lübeck (2016), realizaram um levantamento com interferometria de radar de abertura sintética de banda $\mathrm{P}$ em uma região de floresta densa pertencente à Floresta Amazônica. Os autores utilizaram 42 pontos de GPS de precisão com valores altimétricos e compararam com o MDT gerado através da interferometria de radar em uma área de $50 \mathrm{~km}^{2}$. Os resultados obtidos apontaram que 20 pontos (47,6 \% do total de pontos) apresentaram diferença menor que $1 \mathrm{~m}$, sendo que a menor diferença foi de $-0,05 \mathrm{~m}$ e a maior foi de $-2,86 \mathrm{~m}$.

Ademais, a vegetação também gera sombras que afetam a qualidade dos modelos, dificultando a distinção entre os pontos que pertencem ao solo ou à vegetação, causando perdas de informação. Como o levantamento foi realizado em dia nublado, as sombras foram minimizadas, o que contribuiu para a qualidade dos produtos gerados.

\subsection{CARACTERÍSTICA DA VEGETAÇÃO}

Levando em consideração que a bacia do rio Saci constitui-se como uma bacia hidrográfica florestada e não apresenta nenhuma outra feição acima da superfície do terreno além da vegetação, subtraindo o MDT do MDS obtém-se a altura da vegetação através do modelo digital da vegetação (MDV), conforme ilustrado na Figura 13.

Nota-se no MDV locais sem vegetação (valor igual a zero), representando as estradas não pavimentadas $\mathrm{e}$ as áreas livres entre a vegetação esparsa, onde os valores de altitude no MDS e no MDT são iguais. As áreas com reflorestamento de Pinus taeda ssp apresentam vegetação com até $8 \mathrm{~m}$ de altura no MDV e nas áreas com vegetação nativa, a altura pode chegar a $22 \mathrm{~m}$, sendo composta por Araucárias e outras espécies no estrato superior e sub-bosques altamente heterogêneos. Para a validação do MDV foi realizada medição da altura da vegetação em 18 locais ao longo de duas linhas amostrais (Figura 13). Em cada local foram medidos três exemplares, totalizando 54 árvores. A Figura 14 mostra a comparação das alturas da vegetação medidas em campo e aquelas obtidas no MDV, sendo que a maior diferença foi de $-0,9$ $m$ e a menor foi de $0,22 \mathrm{~m}$, com $E P=0,54 m$ e $R^{2}$ $=0,87$.

Utilizando os mesmos perfis da Figura 10 é possível analisar as características da vegetação comparando o MDS com o MDT. No perfil E-W nota-se que até os $155 \mathrm{~m}$ de distância, a diferença altimétrica entre o MDS e o MDT apresenta a altura da vegetação referente à uma parcela do reflorestamento de pinus (Figura 15A). Dos $155 \mathrm{~m}$ até $390 \mathrm{~m}$ de distância do perfil E$W$ a diferença entre os dois modelos representam a heterogeneidade espacial da mata nativa (Figura 15-A). O perfil N-S (Figura 15-B) apresenta apenas a altura do reflorestamento de pinus quando comparado a diferença entre os dois modelos. 


\section{LEVANTAMENTO COM VEÍCULO AÉREO NÃO TRIPULADO PARA GERAÇÃO DE MODELO DIGITAL DO TERRENO EM BACIA EXPERIMENTAL COM VEGETAÇÃO FLORESTAL ESPARSA}

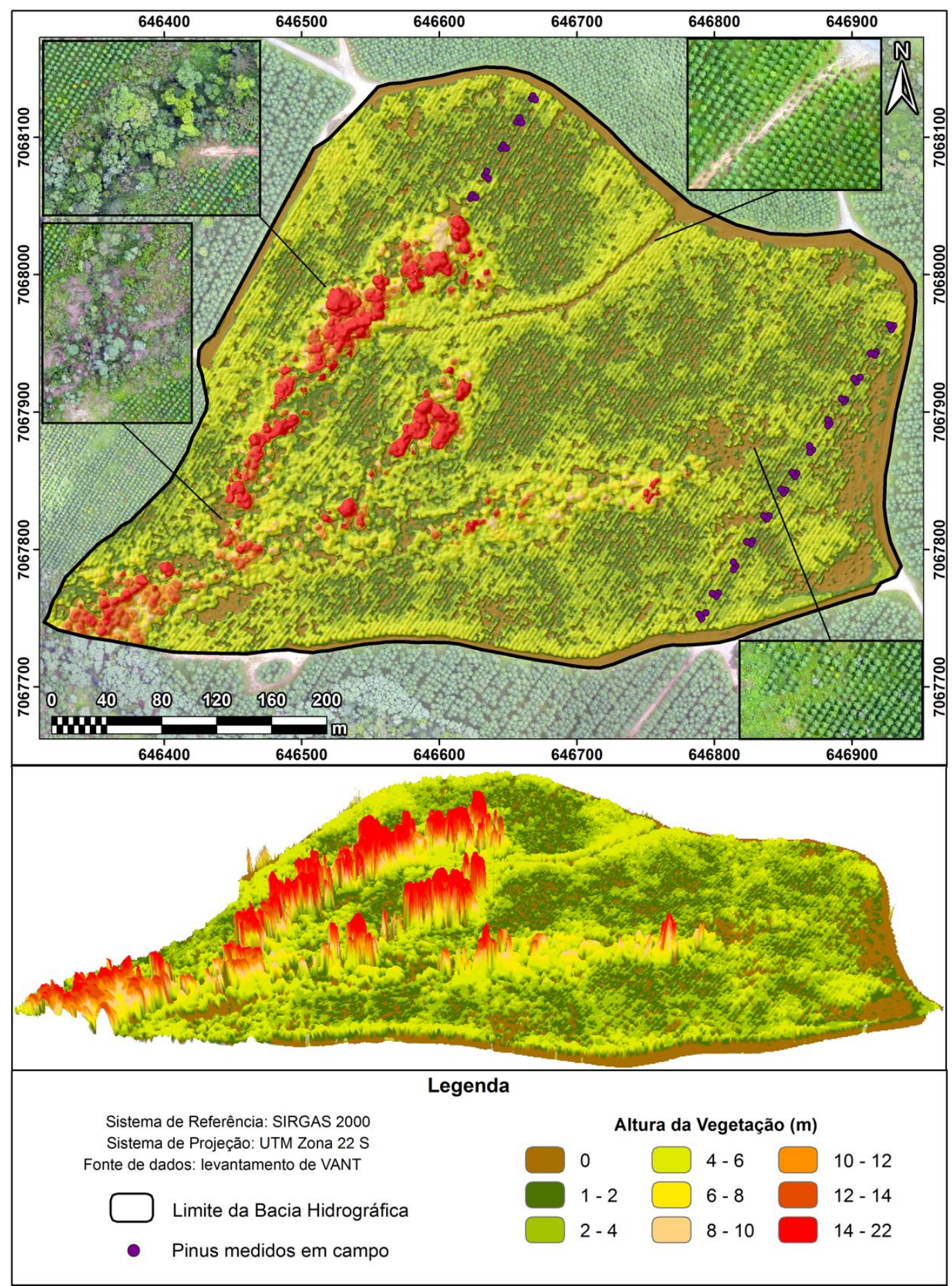

Figura 13 - MDV da bacia experimental do rio Saci. 


\section{LEVANTAMENTO COM VEÍCULO AÉREO NÃO TRIPULADO PARA GERAÇÃO DE MODELO DIGITAL DO TERRENO EM BACIA EXPERIMENTAL COM VEGETAÇÃO FLORESTAL ESPARSA}

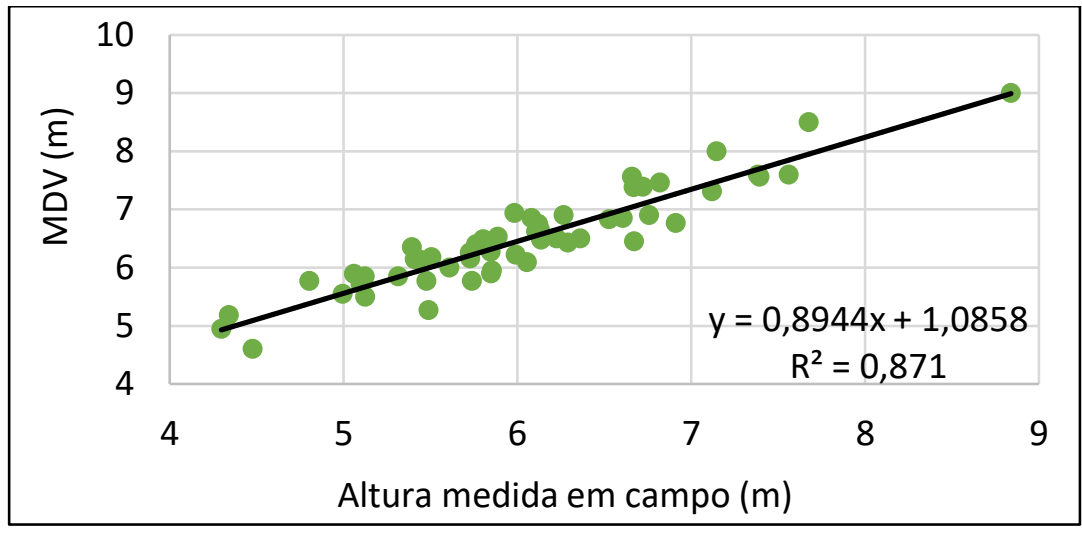

Figura 14 - Altura da vegetação medida em campo e o MDV em relação à linha de tendência.

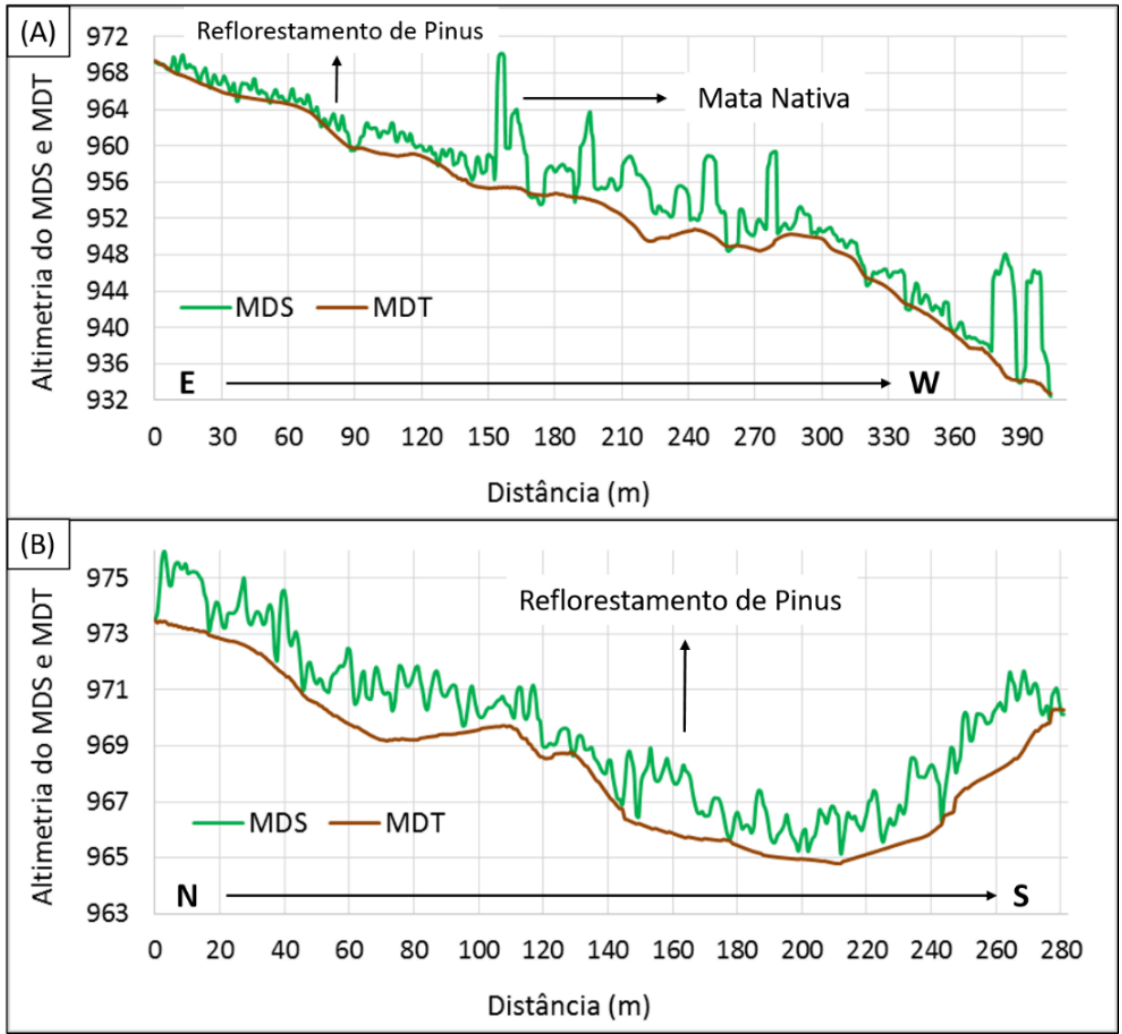

Figura 15 - Altimetria do MDS e altimetria do MDT para o perfil E-W (A) e perfil N-S (B).

\section{CONSIDERAÇÕES FINAIS}

O trabalho mostrou a possibilidade de utilização do VANT para obtenção de MDT em locais com vegetação florestal esparsa, visto que existe uma grande dificuldade de se obter informações das características do relevo nessas áreas. O MDT gerado necessitou de filtragem semiautomática da nuvem de pontos para a retirada da vegetação, uma vez que a classificação e filtragem automática geraram ruídos devido a densidade da vegetação presente na área de estudo, fazendo com que o software de processamento classificasse em alguns casos, árvores de menor altura, como um ponto de solo em áreas de mata nativa de reflorestamento de pinus.

A análise da qualidade interna do MDT foi realizada a partir da comparação com pontos 


\section{LEVANTAMENTO COM VEÍCULO AÉREO NÃO TRIPULADO PARA GERAÇÃO DE MODELO DIGITAL DO TERRENO EM BACIA EXPERIMENTAL COM VEGETAÇÃO FLORESTAL ESPARSA}

de validação obtidos por levantamento topográfico, onde cada ponto foi comparado com o valor do pixel do MDT. A diferença altimétrica máxima foi de $0,53 \mathrm{~m}$ e a mínima foi inferior a $0,01 \mathrm{~m}$ e, os valores de EP e PEC, compatíveis com a escala 1:5.000 (Classe $A$ ).

O MDV, obtido pela subtração do MDS pelo MDT permitiu especializar a altura da vegetação do reflorestamento de pinus e das áreas com vegetação nativa. A validação do MDV indicou que a maior diferença foi de $-0,9 \mathrm{~m}$ e a menor foi de 0,22 $\mathrm{m}$ e $E P=0,54 \mathrm{~m}$.

\section{REFERÊNCIAS}

ABER, J. S.; MARZOLFF, I; RIES, J. Smallformat aerial photography: Principles, techniques and geoscience applications. Elsevier. 268 p. 2010.

ANAC. Agência Nacional de Aviação Civil. Orientações para usuários de drones. Assessoria de comunicação social (ASCOM), ed. 1, 2017.

ARAKI, H. Fusão de informações espectrais, altimétricas e de dados auxiliares na classificação de imagens de alta resolução espacial. 2005. Tese (Doutorado em Ciências Geodésicas) - Setor de Ciências da Terra, Universidade Federal do Paraná, Curitiba, 2005.

ALVEZ JR, L. R.; CÔRTES, J. B. R.; FERREIRA, M. E. Validação de mosaicos aerofotogramétricos utilizando fotografias obtidas com câmera digital não métrica acoplada a um VANT. In: Congresso Brasileiro de Cartografia (CBC), Gramado - RS. Anais, p. 15, 2014.

COSTA, G. C.; SILVA, D. C.; Pré-sinalização de pontos de apoio em aerofotogrametria com câmeras de pequeno formato. In: IV Simpósio Brasileiro de Ciências Geodésicas e Tecnologias da Geoinformação, Recife. Anais, p. 001-009, 2012.

CRUZ, C. B. M.; BARROS, R. S.; CARDOSO, F. V.; REIS, F. B.; ROSÁRIO, L. S.; BARBOSA, S. S; RABACO, L. M. L.; LOURENÇO, J. S. Q. Avaliação da exatidão planialtimétrica dos modelos digitais de superfície (MDS) e do terreno (MDT) obtidos através do LIDAR. Anais XV Simpósio Brasileiro de Sensoriamento Remoto - SBSR, Curitiba: INPE, p. 5463, 2011.
DANDOIS, J. P.; ELLIS, E. C. Remote sensing of vegetation structure using computer vision. Remote Sensing, v. 2, p. 1157-1176, 2010.

DSG. Diretoria de Serviço Geográfico. Norma da Especificação Técnica para Aquisição de Dados Geoespaciais Vetoriais de Defesa da Força Terrestre (ET ADGV Defesa F Ter). 2a Edição. Brasília, 2016.

EVANS, I. S. Geomorphology Geomorphometry and landform mapping: What is a landform? Geomorphology, v. 137, n. 1, p. 94-106, 2012.

FERREIRA, A. M. R. Avaliação de câmara de pequeno formato transportada por veículo aéreo não tripulado - VANT, para uso em aerolevantamentos. 97 f. Dissertação (Mestrado em Geociências) - Instituto de Geociências, Universidade de Brasília, Brasília, 2014.

GABOARDI, C.; LÜBECK, D. Precisão altimétrica de modelo digital do terreno sob a vegetação obtido por interferometria de radar de abertura sintética de banda P. Revista Brasileira de Geografia, v. 61, n. 2, p. 67-81, 2016.

HUGENHOLTZ, C. H.; WHITEHEAD, K.; BROWN, O. W.; BARCHYN, T. E.; MOORMAN, B. J.; LECLAIR, A.; RIDDELL, K.; HAMILTON, T. Geomorphological mapping with a small unmanned aircraft system (sUAS): Feature detection and accuracy assessment of a photogrammetrically-derived digital terrain model. Geomorphology, v. 194, p.16-24, 2013.

HUNG, M. N. W. B.; MARANGON, F. H. S.; SANTOS, I. Comparação entre $O$ índice topográfico e o tasseled cap wetness na estimativa da umidade do solo na bacia hidrográfica do rio Corredeiras - SC. Anais XVII Simpósio Brasileiro de Geografia Física Aplicada, Campinas, v. 1, p. 442-453, 2017.

JÚNIOR, L. R. A.; CÔRTES, J. B. R.; SILVA, J. R.; FERREIRA, M. E. Validação de ortomosaicos e modelos digitais de terreno utilizando fotografias orbitais com câmera digital não métrica acoplada a um VANT. Revista Brasileira de Cartografia, $\mathrm{n}$. 67/7, p. 1453-1466, 2015.

MANCINI, F.; DUBBINI, M.; GATTELLI, M.; STECCHI, F.; FABBRI, S.; GABBIANELLI, G. Unmanned Aerial Vehicles (UAV) for HighResolution Reconstruction of Topography: The Structure from Motion Approach on Coastal 


\section{LEVANTAMENTO COM VEÍCULO AÉREO NÃO TRIPULADO PARA GERAÇÃO DE MODELO DIGITAL DO TERRENO EM BACIA EXPERIMENTAL COM VEGETAÇÃO FLORESTAL ESPARSA}

Environments. Remote Sensing, v. 5, p. 68806898, 2013.

MARZOLFF, I.; POESEN, J. The potencial of 3D gully monitoring with GIS using high-resolution aerial photography and a digital photogrammetry system. Elsevier, Geomorphology 111, p. 48-60, 2009.

PIX4D. Pix4Dmapper 4.1 User manual. Pix4D AS, Switzerland, 2017.

PONZONI, F. J.; SHIMABUKURO, Y. E.; KUPLICH, T. M. Sensoriamento remoto da vegetação. 2a edição - atualizada e ampliada, São Paulo, Oficina de Textos, 2015.

RODRIGUES, A. A. Uso de veículos aéreos não tripulados para mapeamento e avaliação de erosão urbana. 140 f. Dissertação (Mestrado em Geografia) - Programa de Pós-graduação em Geografia, Universidade Federal de Goiás, Goiânia, 2016.

SILVA, D. C.; TOONSTRA, G. W. A.; SOUZA, H. C. S.; PEREIRA, T. A. J. Qualidade de ortomosaicos de imagens de VANT processados com os softwares APS, PIX4D e PHOTOSCAN. In: V Simpósio Brasileiro de Ciências Geodésicas e Tecnologias da Geoinformação, Anais. Recife, 2014.

SILVA, C. A.; SOUTO, M. V. S.; DUARTE, C. R.; BICHO, C. P.; SABADIA, J. A. B. Avaliação da acurácia dos ortomosaicos e modelos digitais do terreno gerados pelo MVANT/DNPM. Revista
Brasileira de Cartografia, n. $67 / 7$, p. $1479-1495$, 2015a.

SILVA, C. A; DUARTE, C. R.; SOUTO, M. V. S.; SABADIA, J. A. B. Utilização de VANT para geração de ortomosaicos e aplicação do Padrão de Exatidão Cartográfica (PEC). In: Simpósio Brasileiro De Sensoriamento Remoto, 14. (SBSR), João Pessoa. Anais, p. 1137-1144, 2015b.

SILVA, C. A.; DUARTE, C. R.; SOUTO, M. V. S.; SANTOS, A. L. S.; AMARO, V. E.; BICHO, C. P.; SABADIA, J. A. B. Avaliação da acurácia do cálculo de volume de pilhas de rejeito utilizando VANT, GNSS e LiDAR. Boletim de Ciências Geodésicas, v. 22, n. 1, p. 73-94, 2016.

TURNER, D.; LUCIEER, A.; WATSON, C. An automated technique for generating georectified mosaics from ultra-high resolution Unmanned Aerial Vehicle (UAV) imagery, based on Structure from Motion (SFM) point clouds. Remote Sensing, v. 4, p. 1392-1410, 2012.

UNGER, K.; POCK, T.; GRABNER, M.; KLAUS, A.; BISCHOF, H. A variation approach to semiautomatic generation of digital terrain models. Institute for computer graphics and vision, Graz University of Technology, 2009.

WESTOBY, M. J.; BRASINGTON, J.; GLASSER, N. F.; HAMBREY, M. J.; REYNOLDS, J. M. "Structurefrom-Motion" photogrammetry: A low-cost, effective tool for geoscience applications. Geomorphology, v. 179, p. 300-314, 2012. 